\title{
INTERVENCIÓN NORMATIVA ANTE LOS RIESGOS PSICOSOCIALES LABORALES CON PERSPECTIVA DE GÉNERO
}

\author{
Normative intervention in the face of occupational psychosocial risks with a \\ gender perspective
}

\author{
Nereida Castro Trancón*
}

Universidad de Oviedo, España

\begin{abstract}
RESUMEN
Las características del empleo femenino conducen a que determinados riesgos psicosociales sean prevalentes en las trabajadoras. Incluso la doble presencia y el acoso laboral, tanto sexual como por razón de sexo, podrían ser considerados como factores específicos de género. El tratamiento jurídico de los riesgos psicosociales, que también debería incluir la perspectiva de género, resulta todavía insuficiente a pesar de la importancia que actualmente se concede a estos riesgos emergentes, sobre todo a nivel internacional y comunitario. Este estudio aborda la prevención y protección ante los riesgos psicosociales laborales derivados de la precarización del empleo femenino aunando dos perspectivas, la psicológica y la jurídica.

Palabras clave: igualdad de oportunidades, riesgos psicosociales, género, acoso sexual, acoso por razón de sexo.

\section{ABSTRACT}

The characteristics of female employment lead to certain psychosocial risks being prevalent in female workers. Even double presence and workplace harassment, both sexual and based on sex, could be considered as gender-specific factors. The legal treatment of psychosocial risks, which should also include a gender perspective, is still insufficient despite the importance currently attached to these emerging risks, especially at the international and community level. This study addresses the prevention and protection against psychosocial risks at work derived from the precariousness of female employment, combining two perspectives, the psychological and the legal.
\end{abstract}

Keywords: equal opportunities, psychosocial risks, gender, sexual harassment, harassment based on sex.

\footnotetext{
* Correspondencia a: Nereida Castro Trancón. Calle Río Deva, 9, bajo derecha, Llaranes (Asturias), España. - nereidactuniovi@ gmail.com - https://orcid.org/0000-0002-6829-4485

Cómo citar: Castro Trancón, Nereida. (2020). «Intervención normativa ante los riesgos psicosociales laborales con perspectiva de género"; Lan Harremanak, 44, 278-308. (https://doi.org/10.1387/lan-harremanak.22238).

Recibido: 14 noviembre, 2020; aceptado: 16 diciembre, 2020.

ISSN 1575-7048 - elSSN 2444-5819 / (C) 2020 UPV/EHU
} 


\section{Factores y riesgos psicosociales derivados de la situación laboral de las mujeres}

La feminización de la precariedad laboral genera unos riesgos psicosociales, que - aun siendo comunes a ambos sexos- hacen oportuno su análisis con una perspectiva de género. Aunque ya se han realizado estudios de interés en la materia, especialmente en relación con el acoso sexual y el acoso por razón de sexo, cabe afirmar que, sin embargo, a pesar de la evidencia disponible sobre la importancia de aquellos riesgos para las mujeres, son todavía necesarias las aportaciones que profundicen en la inclusión de aquella perspectiva.

Como es sabido en la Ley 31/1995, de 8 de noviembre, de Prevención de Riesgos Laborales (en adelante, LPRL) el riesgo laboral se define como «la posibilidad de que un trabajador sufra un determinado dańo derivado del trabajo. Para calificar un riesgo desde el punto de vista de su gravedad, se valorarán conjuntamente la probabilidad de que se produzca el daño y la severidad del mismo" (art. 4 LPRL). Esta Ley no hace ninguna referencia explícita a los riesgos psicosociales, aunque, ciertamente, al establecer la obligación del empresario de "garantizar la seguridad y la salud de los trabajadores a su servicio en todos los aspectos relacionados con el trabajo» (art. 12, LPRL) deben considerarse incluidos aquellos aspectos asociados a la organización del trabajo. Se debe acoger, además, el concepto de salud como la define la Carta Constitucional de la Organización Mundial de la Salud de 1946, entendida como «el estado completo de bienestar físico, mental y social y no solamente la ausencia de afecciones o enfermedades» (OMS, 2006).

En relación con los aspectos psicosociales conviene realizar algunas precisiones conceptuales y terminológicas. Así, según Moreno Jiménez $(2011,7)$ cabe distinguir entre factores psicosociales, factores psicosociales de riesgo y riesgos psicosociales:

Los factores psicosociales «comprenden aspectos del puesto de trabajo y del entorno de trabajo, como el clima o cultura de la organización, las funciones laborales, las relaciones interpersonales en el trabajo y el diseño y contenido de las tareas» (OIT, 1998, 2).

El concepto de factores psicosociales se extiende también al entorno existente fuera de la organización (por ejemplo, exigencias domésticas) y a aspectos del individuo (por ejemplo, personalidad y actitudes) que pueden influir en la aparición del estrés en el trabajo.

Las expresiones organización del trabajo y factores organizativos se utilizan muchas veces de manera intercambiable con factores psicosociales para hacer referencia a las condiciones de trabajo que pueden conducir al estrés (OIT, 1998, 2).

Por otro lado, los factores psicosociales de riesgo se refieren a la probabilidad que tienen las condiciones organizacionales de tener efectos perjudiciales 
para la salud, debido a que son disfuncionales y actúan como desencadenantes de tensión y estrés laboral (Moreno Jiménez, 2011, 7; Rodríguez-Muñoz, 2017, 16-18). Y, por último, los riesgos psicosociales serían aquellas situaciones laborales, que, a diferencia de los factores psicosociales de riesgo, «tienen una alta probabilidad de dañar gravemente la salud de los trabajadores (...) y que afectan a los derechos fundamentales del trabajador» (Moreno Jiménez, 2011,8). Estos deben entenderse como la interacción entre los factores organizacionales del trabajo (y no únicamente las condiciones materiales del mismo) los factores personales o subjetivos y los relacionales, grupales, interpersonales y sociales. Y que es dicha interacción la que genera una situación que deriva en consecuencias negativas para la salud, principalmente psíquica (García Jiménez y Olarte Encabo, 2010, 18).

Cox y Griffiths (1996, 127-146) diferencian estos conceptos poniendo de manifiesto que los factores de riesgo psicosociales hacen referencia a las características del trabajo y del entorno, del contexto social y organizacional que, junto con las características individuales de la persona trabajadora, tienen la probabilidad de generarle daños. Mientras que los riesgos psicosociales serían los efectos derivados de la exposición a dichos riesgos, que tienen una alta probabilidad de afectar a la salud de la persona trabajadora; sus consecuencias dependerán, además, de la vulnerabilidad de cada persona concreta. Es decir, «los factores de riesgo psicosocial son la causa potencial, mientras que los riesgos psicosociales constituyen el efecto por la exposición a los factores de riesgo» (Castaño, Rueda Ruíz, Alcedo Rodríguez y García Izquierdo, 2017, 358). En este sentido y siguiendo las líneas de estas definiciones, en el siguiente epígrafe se abordará una definición de riesgo psicosocial laboral en consonancia con el marco legislativo actual.

A continuación, se analizarán los diferentes factores de riesgos psicosociales generados por la situación laboral de las mujeres, entre ellos, muy brevemente, el acoso sexual y el acoso por razón de sexo como riesgos psicosociales específicos de género que, como se ha dicho, ya han merecido una mayor atención doctrinal. Dentro de los factores de riesgos psicosociales se podría situar también la doble presencia como específico de género, ya que recae sobre las mujeres la necesidad de responder a las demandas del trabajo doméstico y a las del trabajo asalariado, asumiendo unas cargas que, además de suponer un conflicto trabajo-familia, son una variable muy condicionante a la hora de tomar decisiones de carácter laboral, tales como el ejercicio de los derechos a la adaptación del horario de trabajo, la reducción de la jornada laboral o la excedencia por cuidado de familiares.

\subsection{Inseguridad laboral}

Uno de estos factores de riesgo psicosocial generados por la situación laboral y la feminización de la precariedad laboral sería la percepción de inseguridad la- 
boral, definida por la literatura científica psicológica, como «la incapacidad percibida para mantener la continuidad laboral ante una situación de amenaza del trabajo" (Greenhalgh y Rosenblatt, 1984, 440). La inseguridad laboral como percepción, supone la anticipación de un suceso negativo, en este caso la pérdida de empleo, y de sus consecuencias también negativas para el bienestar económico, psicológico y social de las personas trabajadoras. Esta incertidumbre y ambigüedad respecto a la situación laboral hace que la persona trabajadora no pueda desarrollar estrategias de afrontamiento efectivas y apropiadas para gestionar esa situación de posible desempleo, como se hace ante una condición de pérdida de empleo (Sora Miana, Caballer Hernández y Peiró Silla, 2014, 16).

Esa característica anticipatoria que tiene la percepción de inseguridad laboral se refiere, según la teoría del estrés de Lazarus y Folkman, (1984), a que la anticipación de un suceso negativo o estresante, como puede ser la posible pérdida de empleo, puede ser más estresante y tener más consecuencias nocivas que el propio hecho, es decir, que la propia pérdida de empleo. Además, a diferencia del desempleo, la inseguridad laboral no es inmediata, por lo que el malestar es más prolongado, y las consecuencias de la misma, no están tan reconocidas socialmente como el desempleo, lo que supone menor apoyo social e institucional (Salas Nicás, 2018, 68)

La inseguridad laboral se ha convertido en uno de los principales problemas asociados al estrés laboral en Europa, concretamente, el tercer mayor factor de riesgo psicosocial en el entorno laboral (Agencia Europea de Seguridad y Salud en el Trabajo, 2007). Por ello, es uno de los desafíos a abordar por la Unión Europea, que ya ha adoptado distintas medidas, como la flexi-seguridad (Considerando Directiva 1999/70/CE).

Respecto a los factores determinantes en la percepción de inseguridad laboral según Sora Miana et al. $(2014,20)$ estos serían la antigüedad laboral, la empleabilidad en el mercado laboral, el subempleo y los tipos de jornada y contrato, entre otros. También se añadirían a estos factores el aumento de las tasas de desempleo y de mayor duración y el empleo precario (Rebollo Quintela y Muñoz Cantero, 2017, 122-123). Estos factores que determinan la inseguridad laboral están más presentes en el empleo femenino, caracterizado por mayores tasas de desempleo y mayor duración del mismo, por la temporalidad de los contratos y las jornadas parciales.

La antigüedad laboral supone un factor amortiguador en la percepción de inseguridad laboral, pero, debido a que la vida laboral femenina se caracteriza por su discontinuidad e inestabilidad, las mujeres carecen una antigüedad laboral que les permita minimizar los efectos de este factor de riesgo psicosocial. Además, a esto se le suma la baja participación de las mujeres en la empresa y la segregación vertical, lo que generará que, al encontrarse en puestos inferiores, sean más susceptibles de pérdida de empleo. Uno de los factores que opera en 
la discontinuidad laboral es la desigualdad distribución de las tareas del hogar, siendo este factor una de las justificaciones, tanto de la inactividad de las mujeres como de la elección de jornadas parciales. Como ya se ha comentado anteriormente, estas características de parcialidad y temporalidad están más presentes en el empleo femenino, y en muchas ocasiones estas condiciones laborales son involuntarias. Cabe añadir que, la involuntariedad es otra característica de la percepción de la inseguridad laboral.

Respecto a la empleabilidad esta se presenta como «una de las alternativas laborales que dispone un trabajador en el mercado laboral para reducir las experiencias de inseguridad laboral» (Sora Miana et al., 2014, 17). Es decir, la mayor empleabilidad, los mejores puestos y condiciones de trabajo actúan como factores compensatorios de la inseguridad laboral. Por otro lado, el subempleo afecta negativamente a la seguridad laboral, de tal forma que, tanto por sobrecualificación - personas trabajadoras que desempeñan tareas para las tienen superiores cualificaciones - como por subempleo en tiempo - cuando la preferencia de la persona trabajadora no coincide con su tipo de jornada o de contrato, principalmente cuando se prefiere una jornada completa y un contrato permanente- las personas trabajadoras experimentan mayores niveles de inseguridad laboral, ya que no se consideran el recurso más valorado para la organización (Sora Miana et al., 2014,17).

\subsection{Exigencias emocionales}

El siguiente factor de riesgo psicosocial es la exigencia emocional, que se define como aquellas estrategias necesarias para evitar o gestionar la involucración ante una situación emocional en el trabajo, que deriva de las relaciones interpersonales que implica el puesto de trabajo, y que no se pueden eliminar, por lo que, son características de ciertas ocupaciones que prestan servicios a personas, que además de ser directos, en muchas situaciones tienen una duración determinada en el tiempo y son constantes, por lo que la exposición a este factor de riesgo psicosocial será mayor, como es por ejemplo el caso de los servicios sanitarios o la educación (Moncada, Llorens, Andrés y Molinero, 2014, 29), y otros sectores en los que el control emocional «es considerado un elemento decisivo para la calidad del servicio y para obtener ventaja competitiva» (Martínez Ińigo, 2001, 133). Dentro de esta exigencia emocional también estaría la exigencia de esconder emociones, definida como la capacidad de mantener una apariencia neutral ante el comportamiento de la persona a la que se le presta el servicio o también ante superiores y otro tipo de personal. Esta tarea también es característica de sanidad, enseñanza, servicios sociales, etc. (Moncada, et al., 2014, 29).

Se denomina también trabajo emocional cuando en el rol laboral se requiere que la persona trabajadora exprese o experimente ciertas emociones como parte de su trabajo, es decir, que «el trabajo requiere que la persona trabajadora in- 
duzca o suprima sentimientos con el fin de mantener la apariencia externa que produce en otros el estado mental apropiado" (Russell Hochschild, 1983, 7). El principal antecedente del trabajo emocional es la frecuencia de interacción directa con las personas a las que se les presta el servicio, pero existen 4 factores más que forman el trabajo emocional (Morris y Felfman, 1996; 1997. Tomado de Martínez Inigo, 2001, 141). Uno de estos factores sería la frecuencia de expresión emocional, que aumenta cuando las normas que establece la organización para la expresión de emociones son muy explícitas y el control de su cumplimento es estrecho, cuando la persona que desempeña ese rol laboral es una mujer y cuando la tarea es rutinaria y sistemática, ya que supone normas más precisas.

Otro factor sería la atención requerida por las normas de expresión, que hace referencia a la cantidad de esfuerzo y al nivel de atención que se requiere para poder cumplir con las normas de expresión y de control de emociones. Este factor viene determinado por la duración de la interacción y por la intensidad de la expresión, de tal forma que, las interacciones largas y de mayor intensidad - cuando su mala ejecución va ligada a consecuencias negativas- se requieren mayores niveles de atención y un mayor esfuerzo, lo que conlleva a un mayor malestar.

El tercer factor es la variedad de la expresión referido al número de emociones que la persona trabajadora debe expresar o controlar, de tal forma que, a mayor variedad de emociones, mayores niveles de exigencia emocional tiene que desarrollar la persona. Y, como último factor, tendríamos la disonancia emocional, que aumenta cuando se produce una discordancia entre las emociones experimentadas y las expectativas de la organización sobre esa expresión. También aumenta cuando se intentan controlar todas las vías de expresión de emociones (por ejemplo, cuando además de controlar la expresión verbal también se debe cuidar la expresión no verbal). Según otros autores (Franzway, 2000; Grandey, 2000; Hall, 1993; Hochschild, 1983; Rafaeli, 1989; Schaubroeck y Jones, 2000; Tancred-Sheriff, 1989; Wharton y Erickson, 1995), y según las teorías de socialización diferencial por género, las mujeres desarrollan niveles mayores de trabajo y exigencia emocional, justificado por el rol de expertas emocionales, las mayores expectativas que se depositan sobre ellas respecto a sus habilidades y capacidades para captar e interpretar emociones de otras personas, y por una cuestión de segregación horizontal y de mayor presencia de mujeres en determinadas ocupaciones relacionadas con el cuidado de personas, atención directa al público, etc.

El trabajo emocional como factor de riesgo psicosocial, tiene varias consecuencias negativas para la persona trabajadora y para su bienestar, como indica Martínez Ińigo, 2001, 144-146), citando a varios autores (Erickson y Wharton, 1997; Hochschild, 1983, 1990; Leidner, 1993; Abraham, 1998; Brotheridge y Lee, 
1998; Grandey, 1998; Kruml y Geddes, 2000; Morris y Feldman, 1997; Zapf, Vogt. Seifert, Mertini e Isic, 1999; Richard y Gross, 1999). Una de estas consecuencias en la alienación y el extrańamiento del yo, que deriva de la simulación de forma continuada de emociones que no está experimentando realmente y da lugar a una dificultad para distinguir sus propias emociones reales y como consecuencia final, su identidad. Esta percepción de pérdida de la identidad y de falta de autenticidad está relacionada con síntomas característicos de la depresión.

Otra consecuencia es el burnout o desgaste profesional, reconocido como uno de los principales riesgos psicosociales basados en la evidencia (Moreno Jiménez y Báez León, 2010). En este caso, está relacionado con la disonancia emocional, con el agotamiento emocional, la despersonalización, y, además, el trabajo emocional, también puede provocar interferencias con la ejecución de roles en el ámbito privado, como por ejemplo en la familia. Por último, se encuentran también correlaciones negativas respecto a la satisfacción laboral, a la sintomatología física, principalmente activación cardiovascular con efectos negativos a largo plazo y al rendimiento laboral.

\subsection{Doble presencia o conflicto trabajo-familia}

Este factor de riesgo psicosocial se considera específico de género debido a los roles tradicionales que sitúan a las mujeres en los espacios privado-doméstico y en el desempeño de trabajos no remunerados en este ámbito. Esto, se suma al proceso de incorporación de las mujeres a los espacios públicos donde desarrollan trabajos remunerados, pero sin abandonar las actividades familiares y domésticas (Tereso Ramírez y Cota Elizalde, 2017, 1). Adoptar una perspectiva de género respecto a la doble presencia permite visibilizar la carga excesiva de trabajo que pesa sobre las mujeres.

El conflicto trabajo-familia se define como «una forma de conflicto de rol, en el que las presiones que resultan del trabajo son incompatibles mutuamente en algún aspecto con las presiones familiares» (Greenhouse y Beutell, 1985, 77). Este concepto tiene un sentido bidireccional, ya que se pueden distinguir dos conflictos en los que tanto el trabajo como la familia interfieren de forma recíproca. Estos autores destacaron 3 fuentes principales de conflicto trabajo-familia, que se dan cuando (1) el tiempo dedicado a un rol dificulta el desempeño de otro rol, (2) cuando la tensión que se produce en la realización de un rol interfiere en otro ámbito y (3) cuando la conducta que se desarrolla en un rol es incompatible con las conductas de otro rol. Posteriormente se ańadió otro factor basado en la energía, referido a la falta de esta a la hora de desempeñar las tareas de un rol porque ya ha sido utilizada para otras funciones de otro rol, por lo tanto, el rendimiento será menor.

La doble presencia, como fenómeno de la modernidad tardía, significa la visibilidad del empleo femenino y su legitimación social, pero no la liberación de 
las mujeres del trabajo doméstico o un reparto más equitativo. Y es que, el empleo femenino ha surgido como algo específico en relación con la norma social, y se ha naturalizado la idea de la mujer con una doble adscripción productiva y reproductiva, lo que pondría en duda la individualización femenina (Carrasquer Oto, 2009, 10). Concretamente en España, en 2016, las mujeres dedicaban 38 horas semanales al cuidado o educación de menores, 20 horas semanales a cocinar o hacer labores domésticas y 38 horas semanales al cuidado de personas con discapacidad menores y mayores de 75 años, frente a las 23,11 y 28 horas que dedicaban los hombres respectivamente (INE, 2016). Y es que la realidad laboral femenina está marcada por esta presión que sufren las mujeres a la hora de tener que responder a las demandas del trabajo asalariado y al trabajo doméstico-familiar. La doble presencia se manifiesta en las principales desigualdades entre mujeres y hombres en el ámbito laboral, como serían las tasas de inactividad cuya principal causa es la realización de tareas del hogar, la diferencia de tasa de empleo y la elección de jornadas parciales para poder llevar a cabo el cuidado de personas dependientes y otras obligaciones familiares o personales, el mayor número de excedencias y de mayor duración e incluso abandono del empleo por el cuidado de menores, la sectorización del empleo femenino principalmente el sector servicios, donde las jornadas y los horarios son más flexibles y permiten una mejor conciliación. Estos factores, finalmente desembocan en una menor retribución y una mayor precarización del empleo femenino.

El conflicto trabajo-familia supone una fuente de estrés que tiene tanto consecuencias a nivel organizacional como a nivel familiar. Estas consecuencias pueden darse dentro de un ámbito a otro - del laboral al familiar y viceversa- o dentro del mismo ámbito. Las principales consecuencias serían mayores niveles de insatisfacción laboral e insatisfacción y malestar subjetivo general, mayor intención de abandono de la empresa y efectos a nivel de malestar físico y psíquico, como sintomatología física, agotamiento y estado de ánimo negativo en el trabajo (Ford, Heinen y Langkamer, 2007; Boyar y Mosley, 2007; Hill, 2005; Anderson, Coffey y Byerly, 2002; Mauno, Kinnunen y Pyykkö, 2005. Tomado de Sanz Vergel, 2011, 117-118).

La excepcional crisis sanitaria del COVID-19 ha provocado que la modalidad de teletrabajo haya alcanzado un 34\% de personas teletrabajando (Peiró y Soler, 2020, 5), siendo los sectores que mayor posibilidad ofrecen la educación, los servicios sanitarios y sociales, y los relacionados con la información y comunicación, entre otros. Siendo estos, sectores que recogen una mayor presencia femenina. Esta situación supone una mayor dificultad para las mujeres para conciliar el trabajo y la vida personal y familiar, a la que se ańade la no presencialidad del sistema educativo durante el periodo de estado de alarma, que requiere el replanteamiento del actual reparto de tareas domésticas y de cuidados y afrontar el reto de la corresponsabilidad con el fin de eliminar las consecuencias negativas para la salud y el desarrollo profesional de las mujeres (Ramos y Gómez, 2020, 
5-8). En este sentido, el Real Decreto-ley 28/2020, de 22 de septiembre, de trabajo a distancia, entre otras medidas, recoge el derecho a la prevención de riesgos laborales y su aplicación normativa en la modalidad de trabajo a distancia, en lo referido tanto a prevención como a evaluación y planificación. Como se viene indicando, el teletrabajo como forma de trabajo a distancia presenta entre otros inconvenientes la ya mencionada falta de conciliación laboral y familiar, y así lo expone el Real Decreto-ley 28/2020, de 22 de septiembre, de tal forma que, en el artículo 4, relativo a la igualdad de trato y de oportunidades y no discriminación, se establece que:

las personas que realizan trabajo a distancia tienen los mismos derechos que las personas trabajadoras presenciales en materia de conciliación y corresponsabilidad, incluyendo el derecho de adaptación a la jornada establecido en el artículo 34.8 del Estatuto de los Trabajadores, a fin de que no interfiera el trabajo con la vida personal y familiar (art. 4.5).

Debido a que, por lo general, el teletrabajo como mecanismo para la conciliación de trabajo y vida familiar recae de forma mayoritaria sobre las mujeres, con el consiguiente perjuicio para su desempeño laboral (Sierra Benítez, 2020, 3), el Real Decreto-ley 28/2020, de 22 de septiembre, remite a la negociación colectiva en el procedimiento y criterios que deben seguirse para evitar la perpetuación de roles de género y fomentando la corresponsabilidad entre mujeres y hombres.

\subsection{El acoso sexual y el acoso por razón de sexo como riesgos psicosociales}

Tomando en consideración los bienes jurídicos afectados por los comportamientos constitutivos de acoso sexual y acoso por razón de sexo, estos deben ser tenidos en cuenta como una forma específica de riesgo laboral debido a que los efectos de las acciones contra la propia dignidad e intimidad de la persona trabajadora tienen una forma, una naturaleza y unas consecuencias concretas (Moreno Jiménez y Báez León, 2010, 31). Efectivamente, la violencia de género en el trabajo ha tenido un reciente tratamiento como riesgo psicosocial, debido a que las estadísticas ponen de manifiesto que existen unos riesgos específicos para las mujeres relacionados con las condiciones de trabajo, como pueden ser el carácter temporal, las responsabilidades familiares y la subrepresentación en la que se encuentran (Pérez del Río, 2007, 188). En esa línea, en la Nota técnica de prevención N. ${ }^{\circ} 507$, sobre acoso sexual en el trabajo, se recoge que estas formas de violencia de género en el ámbito laboral repercuten sobre la satisfacción laboral, incrementa los intentos de evitar tareas e incluso el abandono del trabajo, provocan una disminución de la productividad y menor motivación (Instituto Nacional de Seguridad e Higiene en el Trabajo, 1999). Así mismo, tanto el acoso sexual como el acoso moral y discriminatorio, en cuanto formas de acoso $\mathrm{y}$ violencia en el trabajo, fueron recogidos como riesgos laborales psicosocia- 
les en el Criterio Técnico 69/2009 de la Dirección General de la Inspección de Trabajo y Seguridad Social.

Esas conductas de acoso generan consecuencias graves para la salud física, relacionadas con la sintomatología asociada al estrés, y también se ve afectada la salud psíquica. En sus dos manifestaciones, la violencia de género provoca en la persona que lo sufre una situación psíquica que puede derivar en un trastorno adaptativo con estado emocional ansioso-depresivo ${ }^{1}$, y que, por consecuente, genera una incapacidad temporal para el trabajo que exige una situación de baja (Pérez del Río, 2007, 191). Es por esto, por lo que se consideran como accidente de trabajo tal y como se define en el Protocolo de 2002 relativo al Convenio sobre seguridad y salud de los trabajadores de $1981^{2}$. Así se ha admitido ya en sede judicial, de lo que es muestra la STSJ de Galicia, RS 5818/1996, de 24 enero de 2000, de la que Cabeza Pereiro y Lousada Arochena $(2000,2)$ señalan que, las lesiones, físicas y psíquicas, derivadas de un acoso sexual, deben "considerarse originadas, a los efectos oportunos, de la contingencia de accidente de trabajo", y, por tanto:

si las lesiones corporales, sean físicas o psíquicas, derivadas de acoso sexual laboral son accidente de trabajo, el riesgo de acoso sexual laboral es un «riesgo laboral», esto es «la posibilidad de que un trabajador sufra un determinado daño derivado del trabajo», según lo define el artículo 4.2 LPRL.

A modo de cierre de este epígrafe, respecto a la prevalencia de estos riesgos psicosociales laborales cabe comentar mínimamente que, según los datos del Informe sobre las Exposiciones psicosociales del Instituto Sindical de Trabajo, Ambiente y Salud (2019), las diferencias más significativas respecto a la comparación por sexo aparecen ante la necesidad de desarrollar estrategias para evitar la involucración en una situación emocional derivada de las relaciones interpersonales que implica el trabajo, así como en la exigencia de esconder emociones y mantener una apariencia neutral. Respecto a la incidencia del acoso sexual en el trabajo, los resultados del estudio del Instituto de la Mujer sobre el acoso sexual a las mujeres en el ámbito laboral (2006), indican que «el 14,9\% de las mujeres trabajadoras en España han sufrido alguna situación de acoso sexual en el último año —acoso técnico- . Sin embargo, este porcentaje se reduce hasta el 9,9\%

${ }^{1}$ El trastorno mixto ansioso-depresivo supone un solapamiento clínico entre los trastornos de ansiedad y depresión cuando ninguno de los síntomas de ambos componentes predomina claramente ni tiene la intensidad suficiente para justificar su diagnóstico por separado (Lemos Giráldez, Serafín (2000, 213) Psicopatología general. Madrid: Síntesis).

2 Tal y como define la OIT «el término «accidente del trabajo» designa los accidentes ocurridos en el curso del trabajo o en relación con el trabajo que causen lesiones mortales o no mortales». (art. 1 a) del Protocolo de 2002 relativo al Convenio sobre seguridad y salud de los trabajadores de 1981) Consultado en: https://www.ilo.org/dyn/normlex/es/f?p=NORMLEXPUB:12100:0::NO::P1 2100_ILO_CODE:P155 
entre las que perciben haber sufrido acoso sexual —acoso declarado-». Según los datos de la Encuesta de Población Activa de 2005, se estima que 1.310.000 trabajadoras han sufrido en España alguna situación de acoso sexual en su trabajo en el último año - acoso técnico-, aunque, son 835.000 las mujeres que lo han vivido como tal —acoso declarado-.

\section{Tratamiento jurídico de los riesgos psicosociales}

\subsection{Normativa internacional}

En lo referente a riesgos psicosociales, no existen Convenios de la Organización Internacional del Trabajo que hagan referencia expresa a su tratamiento y protección. Sin embargo, las obligaciones preventivas frente a ellos pueden considerarse incluidas en las disposiciones de carácter general en materia de seguridad y salud en el trabajo. Efectivamente, la OIT cuenta con varios instrumentos entre los que destaca el Convenio 155, de 22 de junio de 1981, sobre seguridad y salud de los trabajadores, donde se define la salud no solo como la ausencia de afecciones y enfermedades, sino que también se incluyen aquellos elementos físicos y mentales que la afecten (art. 3.e. C155). Cierto es que este Convenio no hace referencia explícita a los agentes sociales y organizacionales que puedan desencadenar riesgos para la salud de las personas trabajadoras, y únicamente se limita a citar los agentes físicos, biológicos y químicos (art. 11.f. C155). Sin embargo, sí que alude a que las políticas deben ir dirigidas, entre otros aspectos, a la adaptación de la organización del trabajo a las capacidades físicas y mentales (art. 5.b. C155), lo que se puede reconocer como un claro componente psicosocial. Por su parte, la Recomendación 164, de 22 de junio de 1981, sobre seguridad y salud de los trabajadores, incluye dentro de una de las Esferas de Acción Técnicas «la prevención de tensiones físicas o mentales provocadas por las condiciones de trabajo y perjudiciales para la salud» (punto 3.e). Dicho Convenio va también acompañado del Protocolo 155, de 20 de junio de 2002, en el que se reconoce la enfermedad profesional como aquella contraída por la exposición a factores de riesgo que resulte de la actividad profesional (art. 1.b). Entre estos factores de riesgo podríamos intuir que también se incluyen los factores de riesgos psicosociales, aunque el texto no lo establezca específicamente (Ballester Pastor, 2013, 15).

El siguiente Convenio de la OIT que conecta con algún aspecto relativo a los riesgos psicosociales laborales y a su prevención sería el Convenio 161, de 26 de junio de 1985, sobre los servicios de salud en el trabajo. Su primer artículo hace referencia a la necesidad de designar unos servicios de salud para «(i) establecer y conservar un medio ambiente de trabajo seguro y sano que favorezca una salud física y mental óptima en relación con el trabajo; (ii) adaptar el trabajo a las capacidades de los trabajadores, habida cuenta de su estado de salud física y 
mental» (art. 1.a). Así mismo el Convenio 187, de 15 de junio de 2006, sobre el marco promocional para la seguridad y salud en el trabajo y su Recomendación 197, de 15 de junio de 2006, siguen la misma línea, dentro de la promoción de una cultura de prevención. Con todo, la referencia más clara hacia los riesgos psicosociales aparece en la Recomendación 194, de 20 de junio de 2002, sobre la lista de enfermedades profesionales, donde se incluyen los trastornos mentales y del comportamiento como el estrés postraumático y «otros trastornos mentales o del comportamiento" (anexo, punto 2.4, R194). No obstante, a pesar de que la inclusión de los trastornos mentales y de comportamiento como enfermedades profesionales, y de que a lo largo de los distintos convenios y recomendaciones se tienen en cuenta los factores de riesgo que generen estas problemáticas como las condiciones laborales y organizacionales, debe concluirse que los riesgos psicosociales laborales aparecen en la normativa descrita de forma muy escasa y poco definida, lo que afecta al tratamiento jurídico de los riesgos psicosociales, a su prevención e intervención.

También se podrían conectar los riesgos psicosociales con el concepto de «trabajo decente», al que alude por primera vez la Memoria del Director General presentada a la 87. a reunión de la Conferencia Internacional del Trabajo sobre trabajo decente. En ella se hace mención a la necesidad de implementar una política de género, ya que la actividad de la OIT se limita únicamente a «declaraciones sobre la igualdad para la mujer y a sus derechos» (OIT, 1999), pero no existe una política integrada que responda a la situación de evolución del empleo y la actuación de la mujer en la población activa, por la que se han generado nuevas condiciones de vida y de trabajo que han quedado al margen de la legislación y la protección social, dando como resultado que las mujeres hayan sido las principales víctimas de este cambio debido a la segregación laboral de las mismas en los sectores menos protegidos y con mayor inseguridad de empleo.

Cabe mencionar también, de manera específica y en relación con el acoso sexual y por razón de sexo en el ámbito laboral, la importancia del recientemente adoptado Convenio 190 de la OIT de 21 de junio de 2019, sobre la violencia y el acoso, que protege a las personas trabajadoras, sin tener en cuenta su tipo de contrato (art. 2), de estas situaciones tanto si ocurren durante el desarrollo del trabajo, incluyendo las comunicaciones vía tecnológica, como en los espacios y lugares del trabajo y también en los trayectos entre el domicilio y el lugar de trabajo (art. 3). Respecto a este Convenio, España había iniciado los trámites para proceder a su ratificación en marzo de 2020; sin embargo, esta aún no ha tenido lugar. Esa ratificación supondrá, cuando se produzca, la adopción por fin de «un enfoque inclusivo, integrado y que tenga en cuenta las consideraciones de género para prevenir y eliminar la violencia y el acoso en el mundo del trabajo». Enfoque que tendrá en cuenta también la violencia y el acoso que implique a terceros (art. 4.2. C190). Además, su ratificación supondría una reorganización y actualización de los conceptos existentes en las distintas normas 
de nuestro ordenamiento jurídico, lo que sería una buena oportunidad para solucionar el debate conceptual sobre los elementos definitorios de los distintos comportamientos, conductas y daños que causan y/o son susceptibles de causar (Pons Carmena, 2020, 55-56). Indica la autora que su ratificación, junto con la STC 56/2019, de 6 de mayo de 2019, eliminaría la distinción entre acoso moral y acoso discriminatorio, ya que:

en ambos casos se apuesta por un concepto amplio, que debe tener como referencia principal la protección de la persona que presta servicios por cuenta ajena "frente a toda conducta que pueda poner, porque así lo quiera o porque así resulte, en peligro su integridad y dignidad (arts. 10.1 y $15 \mathrm{CE}$ )». (...) Ni el elemento subjetivo (intencionalidad), ni el elemento reiteración, ni el elemento de resultado (producción efectiva y acreditada de un daño) deben exigirse como constitutivos del tipo jurídico acoso laboral en la doctrina constitucional a partir de la STC 56/2019, de 6 de mayo de 2019, como tampoco lo son en el concepto previsto en el Convenio OIT 190 (art. 1.1.a) y tampoco deberían serlo si se produce la ratificación del mismo.

\subsection{Normativa comunitaria}

Como es sabido, en el marco del Derecho comunitario en materia de seguridad y salud en el trabajo destaca la Directiva Marco 89/391/CEE del Consejo, de 12 de junio de 1989, relativa a la aplicación de medidas para promover la mejora de la seguridad y de la salud de los trabajadores en el trabajo. Esta norma hace mención a la aplicabilidad de sus disposiciones atendiendo a todos los riesgos profesionales, fórmula omnicomprensiva en la que deben entenderse ya incluidos también los riesgos psicosociales. Además, explícitamente se menciona en ella la prevención de los riesgos psicosociales dentro de las obligaciones generales del empresariado, señalando que aquella comprende «la planificación de la prevención buscando un conjunto coherente que integre en ella la técnica, la organización del trabajo, las condiciones de trabajo, las relaciones sociales y la influencia de los factores ambientales en el trabajo» (art. 6.1.g. Directiva 89/391/CEE). Circunstancias todas ellas que constituyen, en definitiva, factores de riesgo psicosociales. Así lo ha entendido el legislador español al trasladar esas previsiones en el artículo 15.1.g) de la LPRL. Conviene poner de manifiesto que también se hace referencia a la evaluación de los riesgos para la salud y la seguridad de las personas trabajadoras con riesgos especiales (art. 9. 1.a. Directiva 89/391/CEE), entre las que se podrían incluir las mujeres, debido a los riesgos específicos que sufren, tales como el acoso sexual y por razón de sexo y la doble presencia.

Por otra parte, cabe mencionar que la Unión Europea también desarrolla políticas públicas que se concretan en documentos de soft law que también abordan la problemática de los riesgos psicosociales. Así, según la Estrategia comunitaria de salud y seguridad en el trabajo, 2002-2006 (Comisión de las Comuni- 
dades Europeas, 2002) se tiene en cuenta el proceso de cambio y transición del mercado laboral, así como la evolución de la población activa, donde se incluye el crecimiento del empleo femenino. De esta forma se considera la dimensión de género en la evaluación y control de la calidad del empleo. También se incluye dentro de esta evolución, la diversificación de las formas de empleo, tales como los trabajos temporales y los horarios atípicos. Factores, como se expuso, considerados de riesgos psicosociales y especialmente conectados con la situación laboral de las mujeres (vid. supra. epígrafe 1). Tras este diagnóstico de las nuevas situaciones laborales, se propone el tratamiento normativo de los denominados «riesgos emergentes», entre los que se encontrarían riesgos psicosociales tales como el trabajo precario, el trabajo irregular y flexible, la violencia y el acoso laboral y la deficiente y la incompatibilidad entre vida y trabajo (Agencia Europea de Seguridad y Salud en el Trabajo, 2007). Esta Estrategia plantea la necesidad de «fomentar un verdadero bienestar en el trabajo que sea tanto físico como moral o social y que no se mida sólo por la ausencia de accidentes o de enfermedades profesionales» (Comisión de las Comunidades Europeas, 2002).

Bajo este pretexto, y dentro de una las medidas complementarias para cumplir este objetivo, se incluye, en torno a la salud laboral, la prevención de los riesgos psicosociales, que son tratados como un nuevo riesgo laboral que deriva de la evolución del mundo del trabajo. Posteriormente, la Comisión Europea adoptó, el 21 de febrero de 2007, la nueva Estrategia Comunitaria de Salud y Seguridad en el Trabajo, para mejorar la calidad y la productividad en el trabajo, donde se tiene en cuenta que:

la participación de las mujeres en el empleo sigue aumentando, y en muchos casos va acompañada de una segregación entre los sexos en el mercado laboral. Por consiguiente, es preciso tener más en cuenta los aspectos de salud y seguridad específicos de las mujeres (Comunicación de la Comisión al Parlamento Europeo, al Consejo, al Comité Económico y Social y al Comité de las Regiones, de 21 de febrero de 2007, p. 4)

En los documentos comunitarios también se hace referencia al aumento de algunos tipos de enfermedades profesionales, entre ellas, las «alteraciones derivadas de presiones psicológicas», y al desarrollo de nuevos riesgos, donde se menciona el acoso sexual. Ambas Estrategias mencionan la necesidad de investigar, prevenir y consensuar políticas, así como mejorar y reforzar la aplicación de la legislación comunitaria ante estos nuevos riesgos, haciendo especial mención a la salud mental en el trabajo. En concreto, en relación con los riesgos psicosociales, en la Estrategia 2002-2006, se hace referencia a «la creación de una nueva legislación relativa a los riesgos emergentes» entre los que se encuentran varios riesgos psicosociales, principalmente la violencia en el trabajo.

Una vez expuestas, sin ánimo de exhaustividad, las principales disposiciones comunitarias de referencia, es preciso señalar que la doctrina ha puesto de relieve 
que el contexto normativo actual no favorece la unificación en materia de condiciones de trabajo, lo que se traduce en un tratamiento "peculiar» de los riesgos psicosociales (Ballester Pastor, 2013, 2-6). A pesar de esta "desnormativización» de los riesgos psicosociales que indica esta autora, se desarrollaron entre 2004 y 2007 dos Acuerdos Marco Europeos, uno sobre el estrés laboral, de 8 de octubre de 2004, y otro sobre el acoso y la violencia en el trabajo, de 26 de abril de 2007, que, a pesar de sus limitaciones, fueron imprescindibles para el reconocimiento de los riesgos psicosociales por parte de los Estados miembros y que estos fueran incluidos en las normas preventivas, con especial atención a aquellos con un carácter y consecuencias más graves, como el acoso discriminatorio. Cabe destacar que la violencia en el trabajo como riesgo psicosocial ha sido el tipo de riesgo más fácil de identificar y sobre el que existe más acuerdo, incluso en los casos de violencia externa procedente de terceros, que, como se refiere en el acuerdo en el ámbito de la Unión Europea denominado "Directrices multisectoriales» también debe formar parte de la evaluación de riesgos (García Viña, 2013, 6).

Finalmente, es oportuno señalar que, la realidad europea es que existe una diversidad de modelos reguladores y de experiencias aplicativas en los casos en los que sí existe una regulación de los riesgos psicosociales, como ocurre en Suecia, Finlandia, Noruega, Dinamarca y Holanda (García Jiménez y Olarte Encabo, 2010, 53). Siguiendo esta línea, Velázquez Fernández (2020, 61-62) afirma que la regulación de estos riesgos conlleva particularidades debido a este elemento de indefinición, que no se da en otras disciplinas preventivas, en las que sí se establecen unas medidas concretas exigibles a las empresas. En suma, si la legislación precisara también las obligaciones en materia de riesgos psicosociales la existencia de unas disposiciones legales claras mejoraría la calidad de las acciones llevadas a cabo en las organizaciones.

\subsection{Normativa estatal}

A nivel estatal, España no cuenta con una legislación específica en materia de riesgos psicosociales, sino con una regulación genérica que provoca incertidumbres sobre el alcance del deber de prevención en este terreno. No existe un consenso científico sobre la forma concebir y tratar los riesgos psicosociales en el trabajo, ni por tanto tampoco hay una teoría unitaria y consensuada sobre estos riesgos (Gollac y Bordier, 2011, 23), lo que se ha traducido en esa ausencia de regulación específica y por consiguiente en una carencia en materia de intervención y prevención (García Jiménez y Olarte Encabo, 2010, 16).

La definición de riesgos psicosociales debe contener aquellos factores organizacionales, relacionales y personales que en interacción tengan una alta probabilidad de generar riesgos para la salud, entendiéndola en un sentido amplio. Siguiendo estas líneas, la definición que debe aplicarse en el marco legislativo actual, según Molina Navarrete $(2011,2)$ sería aquella que entienda los riesgos psicosociales como: 
la relación de probabilidad de que un trabajador sufra un determinado daño a su salud física y psíquica derivado de la interacción entre la organización del trabajo: condiciones de trabajo, sistemas productivos y contenido de su tarea, su ambiente o entorno, interno - relaciones sociales entre el personal de las empresas (dirección, compañeros) - y externo -relaciones del personal con terceras personas implicadas en su actividad (clientes, usuarios...), y sus características personales.

Como ya se anticipó, a pesar de esa falta de regulación específica, sí se puede entender que en el concepto genérico de riesgo laboral se incluyen «todas aquellas otras características del trabajo, incluidas las relativas a su organización y ordenación, que influyan en la magnitud de los riesgos a los que esté expuesto el trabajador» (art. 7.d. LPRL). Reconociéndose estas condiciones de trabajo como generadora de riesgos para la seguridad y la salud de la persona trabajadora. De esta forma, aunque no exista una previsión normativa expresa, sí que implícitamente atiende el ordenamiento español a los riesgos psicosociales como aquellos relacionados con las características de la organización y con las condiciones de trabajo. Así se entiende también en la Sentencia del Tribunal Constitucional 160/2007, de 2 de julio de 2007, al basarse en el art. 14 LPRL, por el que:

en cumplimiento del deber de protección (...) el empresario - y la Administracióndeberá garantizar la seguridad y la salud de los trabajadores a su servicio en todos los aspectos relacionados con el trabajo, imponiéndole, en relación con ello y en el marco de sus responsabilidades, la prevención de los riesgos laborales mediante la adopción de cuantas medidas sean necesarias para la protección de la seguridad y la salud de los trabajadores (STC 160/2007, de 2 de julio de 2007, FJ 5).

Se hace también referencia en la LPRL a los factores psicosociales que se recogen en la definición de Molina Navarrete. Así, respecto al proceso de acción preventiva se hace referencia a su planificación «buscando un conjunto coherente que integre en ella la técnica, la organización del trabajo, las condiciones de trabajo, las relaciones sociales y la influencia de los factores ambientales en el trabajo» (art. 15.1.g LPRL). Dicho artículo:

está reconociendo no sólo el deber de actuar sobre riesgos físicos, probablemente los más tradicionales (...), sino también sobre los riesgos psicosociales, que podríamos calificar como riesgos de «última generación» y que han adquirido relevancia en el ámbito del sector servicios y, en general, a propósito de la discusión sobre las formas de liderazgo y de dirección de personas, a fin de evitar situaciones de acoso y de estrés (Luque Parra y Sánchez Torres, 2008, 108)

Y, por otro lado, aunque de forma muy genérica, se menciona la protección de trabajadores y trabajadoras especialmente sensibles a determinados riesgos, de tal forma que «el empresario garantizará de manera específica la protección de los trabajadores que, por sus propias características personales o estado biológico conocido, incluidos aquellos que tengan reconocida la situación de discapacidad 
física, psíquica o sensorial, sean especialmente sensibles a los riesgos derivados del trabajo. A tal fin, deberá tener en cuenta dichos aspectos en las evaluaciones de los riesgos y, en función de éstas, adoptará las medidas preventivas y de protección necesarias» (art. 25.1 LPRL).

\section{Protección ante los riesgos psicosociales con perspectiva de género}

\subsection{El principio de no discriminación por razón de sexo en el ámbito laboral}

En el plano internacional son numerosas las disposiciones que recogen el derecho al trabajo y a desarrollarlo en unas condiciones equitativas. Entre ellas destaca el artículo 11 de la Convención de Naciones Unidas sobre la eliminación de todas las formas de discriminación contra la mujer, de 18 de diciembre de 1979, que recoge la obligación de los Estados Parte a adoptar medidas para eliminar la discriminación contra la mujer en el ámbito laboral, con el fin asegurar la igualdad de condiciones entre mujeres y hombres. También la OIT ofrece un amplio respaldo respecto a la promoción de la igualdad entre mujeres y hombres en el ámbito laboral que se establece principalmente en la Resolución relativa a la igualdad de género como eje del trabajo decente, de junio de 2009, donde resulta relevante, la mención específica a las desigualdades estructurales a las que se enfrentan las mujeres, y por ello, recogen que se debe incluir en las políticas de empleo la perspectiva de género (art.14 y 15). Se mencionan otros objetivos tales como la reducción de las «situaciones de trabajo precario (...), inseguro e inestable (...) aplicando una perspectiva de género (art. 21), la disminución de la desigualdad de remuneración (art. 18), el aumento de la empleabilidad de las mujeres y su inclusión en actividades y sectores donde predominan los hombres (art. 53) y la adopción de medidas ante la «economía informal, donde las mujeres (...) se encuentran en trabajos precarios, atípicos y mal remunerados» (art. 43). Para su consecución, la Resolución establece que los estados miembros deben ratificar y aplicar los Convenios 100, de 29 de junio de 1951, sobre igualdad de remuneración, y 111, de 1958, sobre la discriminación (empleo y ocupación).

En el Derecho comunitario, la Carta de los Derechos Fundamentales de la Unión Europea, hace referencia a que «la igualdad entre hombres y mujeres deberá garantizarse en todos los ámbitos, inclusive en materia de empleo trabajo y retribución» (art. 23). El Derecho originario recoge también el principio de igualdad entre mujeres y hombres en lo que respecta a las oportunidades en el mercado laboral y al trato en el trabajo (art. 153.1.i TFUE), y siguiendo con lo aquí establecido, el Pacto Europeo por la Igualdad de Género (2011-2020) recoge también que se deben reducir «las desigualdades en cuanto a empleo y protección social, incluidas las diferencias de retribución entre mujeres y hombres» (DOUE 25-5-2011, C155/12, punto 1) mediante medidas para «promover el 
empleo de la mujer (...) y reducir las desigualdades en materia de empleo; eliminar los estereotipos de género (...) con el fin de reducir la segregación por sexos en el mercado laboral; y garantizar una misma retribución para un mismo trabajo o para un trabajo de igual valor (DOUE 25-5-2011, C155/12, apartados a, b y c).

En el Derecho derivado destaca la Directiva 2006/53/CE del Parlamento Europeo y del Consejo, relativa a la aplicación del principio de igualdad de oportunidades e igualdad de trato entre hombres y mujeres en asuntos de empleo y ocupación, que establece que «no se ejercerá ninguna discriminación directa ni indirecta por razón de sexo en los sectores público y privado (...) en relación con: a) las condiciones de acceso al empleo (...); c) las condiciones de empleo y trabajo (art. 14).

A nivel estatal, la Constitución Española (en adelante, CE) recoge la obligación de los poderes públicos de promover las condiciones para que "la igualdad del individuo y de los grupos en que se integra sean reales y efectivas» (art. 9.2. CE) y el principio de igualdad ante la ley y de no discriminación por razón de sexo. Es conocido que el Real Decreto Legislativo 2/2015, de 23 de octubre, por el que se aprueba el texto refundido de la Ley del Estatuto de los Trabajadores (en adelante, ET) recoge en su artículo 17.1 la prohibición de discriminación en las relaciones laborales, de aplicación también en materia de negociación colectiva (art. $90 \mathrm{ET})$.

De una forma más amplia, la Ley Orgánica 3/2007, de 22 de marzo, para la igualdad efectiva de mujeres y hombres (en adelante, LOIEMH) recoge el principio de igualdad de trato entre mujeres y hombres y la ausencia de discriminación, directa o indirecta, por razón de sexo (art. 3), y su integración en las políticas laborales será un criterio general de actuación de los Poderes Públicos (art. 14.2). Esta Ley desarrolla en el Título IV el derecho al trabajo en igualdad de oportunidades bajo distintos preceptos en materia de mejora de la empleabilidad de las mujeres, de conciliación y corresponsabilidad y mediante la elaboración de los planes de igualdad de las empresas y otras medidas de promoción de la igualdad. En relación con los planes de igualdad, el Real Decreto 901/2020, de 13 de octubre, por el que se regulan los planes de igualdad y su registro y se modifica el Real Decreto 713/2010, de 28 de mayo, sobre registro y depósito de convenios y acuerdos colectivos de trabajo, introduce nuevas normas reglamentarias que contribuyen a garantizar el contenido del Capítulo III de la LOIEMH en lo relativo a la promoción de la igualdad real y efectiva entre mujeres y hombres en el ámbito laboral (López Cumbre, 2020, 37).

Concretamente, en materia de riesgos psicosociales laborales el artículo 27.3.c de la LOIEMH incluye dentro del principio de igualdad en la política de salud «la protección, promoción y mejora de la salud laboral», reconociendo también el acoso sexual y el acoso por razón de sexo. También la LPRL recoge, dentro de los 
objetivos de la política en materia de prevención de riesgos para proteger la seguridad y la salud en el trabajo, que «las Administraciones públicas promoverán la efectividad del principio de igualdad entre mujeres y hombres, (...) con el objetivo de detectar y prevenir posibles situaciones en las que los daños derivados del trabajo puedan aparecer vinculados con el sexo de los trabajadores» (art. 5.4).

Por último, dentro de las condiciones de trabajo, en materia de retribuciones, además de los preceptos constitucionales ya comentados sobre la prohibición de discriminación por razón de $\operatorname{sexo}^{3}$, la legislación ordinaria estatal recoge varias disposiciones sobre igualdad retributiva. El ET dedica su artículo 28 a la igualdad de remuneración por razón de sexo y recoge en su apartado primero que «el empresario está obligado a pagar por la prestación de un trabajo de igual valor la misma retribución, satisfecha directa o indirectamente, y cualquiera que sea la naturaleza de la misma, salarial o extrasalarial, sin que pueda producirse discriminación alguna por razón de sexo en ninguno de los elementos o condiciones de aquella». Como señala Martínez Moreno, $(2019,106)$ este artículo:

incorpora una extraña presunción de la existencia de la brecha que presenta otros tantos inconvenientes: primero, se aplica a empresas con plantillas a partir de 50 trabajadores, lo que augura una muy escasa relevancia práctica de esta medida; exige además un promedio de un $25 \%$ de diferencia salarial entre uno y otro sexo, lo que planteará el problema de la forma de medición y el añadido de que esta se lleve a cabo efectivamente (...); y que, por si fuera poco, permite al empresario incluir en el correspondiente registro una justificación de esa diferencia, abriendo una peligrosa espita a actuaciones arbitrarias o difícilmente controlables por parte de la empresa.

Cabe mencionar brevemente el Real Decreto 902/2020, de 13 de octubre, de igualdad retributiva entre mujeres y hombres, que tiene como objeto, a través del principio de transparencia retributiva, «la identificación de discriminaciones, en su caso, tanto directas como indirectas, particularmente las debidas a incorrectas valoraciones de puestos de trabajo (art. 3)», y la obligación de igual retribución por trabajo de igual valor (art.4), conforme al artículo $28.1 \mathrm{ET}$, con el fin de superar el reto de la discriminación retributiva por razón de sexo, y más concretamente, la discriminación indirecta por incorrecta valoración de los puestos de trabajo.

3 En los instrumentos internacionales y comunitarios, ya mencionados, se encuentran varias disposiciones en materia retributiva, como por ejemplo en la Declaración Universal de Derechos Humanos (art. 24.2), en el Pacto Internacional de Derechos Económicos, Sociales y Culturales (art. 7.1.a.i), la Convención sobre la eliminación de todas las formas de discriminación contra la mujer (art. 1.d), el Convenio 100 de la OIT, sobre igualdad de remuneración, la Resolución relativa a la promoción de la igualdad entre hombres y mujeres, a la igualdad de remuneración y a la protección de la maternidad, el artículo art. 157.1 de la Versión Consolidada del Tratado de Funcionamiento de la Unión Europea, la Carta Social Europea (art. 4.3), cuya versión revisada de 1996 no está ratificada por Espańa, la Carta de Derechos Fundamentales (art. 23), la Carta comunitaria de los derechos sociales fundamentales de los trabajadores (apartado 16), y la Directiva 2006/54/CE en el Derecho comunitario derivado (art. 4). 


\subsection{Prevención de la doble presencia}

El conflicto trabajo-familia como factor de riesgo psicosocial cuenta, como se mostró en el epígrafe anterior, con medidas que fomentan y favorecen la conciliación entre la vida laboral y familiar. Sin embargo, estas herramientas y derechos no se aplican desde una perspectiva de prevención de riesgos psicosociales, sino que son «medidas complementarias a las previsiones legales que no observan especiales innovaciones ni enfoques diferenciales en su tratamiento como factores de riesgo psicosocial» (Grau Pineda, 2017, 53).

A nivel organizacional, para fomentar la conciliación trabajo-familia debe existir una cultura flexible y basada en una comunicación abierta, que no se preocupe exclusivamente por la productividad directa, sino también por los recursos humanos. En esta línea, las medidas de apoyo a la conciliación familiar deben ir dirigidas a la organización del tiempo laboral de tal forma que los horarios sean más flexibles que las personas trabajadoras cuenten con un tiempo personal en el que tengan oportunidad de recuperación, para reducir el agotamiento. A diferencia de lo que está ocurriendo estos últimos años, debido a que en la cultura organizacional no se reconoce la importancia de la conciliación familiar, las políticas en esa materia no pueden quedar relegadas a un segundo plano, sino que deben implementarse dentro de un plan estratégico más amplio, donde se lleven a cabo medidas de flexibilidad y de reducción de carga de trabajo (Sanz Vergel, 2011, 123). En este sentido, López Nuñez $(2020,155)$ indica que las organizaciones son fundamentales a la hora de fomentar el equilibrio trabajo-familia, de tal forma que son las que deben «adoptar una cultura de conciliación y corresponsabilidad, un correcto diseño del puesto de trabajo, y el desarrollo de políticas de conciliación». De esta forma, las medidas preventivas deben ir dirigidas a adoptar políticas y medidas laborales, culturales y sociales, desde una perspectiva más integral, que vayan en el sentido de lograr una corresponsabilidad de mujeres y hombres para el cuidado y atención del trabajo doméstico y familiar. Tal y como indican Brunel, López y Moreno (2012, 27-28) la prevención e intervención de los riesgos derivados de la doble presencia deben abordarse desde una actuación múltiple donde, por un lado, las empresas identifiquen, valoren y actúen ante este riesgo, mediante la evaluación de riesgos psicosociales y la negociación de los planes de igualdad. Indican estas autoras que «la experiencia es que la intervención sindical se ha centrado en mejorar la adaptación y distribución del tiempo de trabajo, y en la difusión y ampliación de los derechos recogidos en la normativa igualitaria y la corresponsabilidad relacionados con la conciliación de la vida familiar y laboral». Así mismo, señalan que:

las distintas medidas a adoptar legislativas, laborales, culturales y sociales, en materia de corresponsabilidad deben encuadrarse en una perspectiva más integral orientada a la eliminación de las diversas formas de discriminación por razón de sexo y para 
avanzar en la corresponsabilidad de mujeres y hombres para el cuidado y atención del trabajo doméstico y familiar.

Respecto a las condiciones de trabajo, en materia de conciliación, corresponsabilidad y jornada laboral el Convenio 156 OIT $^{4}$, de 23 de junio de 1981, sobre los trabajadores con responsabilidades familiares, ratificado por España en septiembre de 1985, dispone que, con el objetivo de «crear la igualdad efectiva de oportunidades y de trato entre trabajadores y trabajadoras (...) cada Miembro deberá incluir entre los objetivos de su política nacional el de permitir que las personas con responsabilidades familiares que desempeñen o deseen desempeńar un empleo ejerzan su derecho a hacerlo sin ser objeto de discriminación y, en la medida de lo posible, sin conflicto entre sus responsabilidades familiares y profesionales» (art. 3.1). De tal forma que la responsabilidad familiar no constituya de por sí una causa justificada para poner fin a la relación de trabajo (art. 8). También, la ya mencionada Resolución relativa a la igualdad de género como eje del trabajo decente (vid. supra. subepígrafe 2.1), recoge «la necesidad de que los Estados miembros adoptasen medidas para promover y favorecer un mayor equilibrio entre trabajo y la vida familiar» (punto 28), y que las medidas deben ir también dirigidas a alentar a los hombres a participar en las responsabilidades de cuidado y a que las responsabilidades sean compartidas con el fin de eliminar estereotipos de género que suponen una forma de discriminación en el ámbito laboral (puntos 6 y 17).

En la Unión Europea cabe destacar la nueva Directiva 2019/1158 del Parlamento Europeo y del Consejo, de 20 de junio de 2019, relativa a la conciliación de la vida familiar y la vida profesional de los progenitores y los cuidadores ${ }^{5}$, por la que se deroga la Directiva 2010/18/UE del Consejo. Esta norma recoge como derechos individuales «a) el permiso de paternidad, el permiso parental y el permiso para cuidadores; $\mathrm{y}$ b) fórmulas de trabajo flexible para los trabajadores que sean progenitores o cuidadores" (art. 1 DOUE 12-7-2019, L 188/85), considerando que «las políticas de conciliación de la vida familiar y la vida profesional deben contribuir a lograr la igualdad de género promoviendo la participación de las mujeres en el mercado laboral, el reparto igualitario de las responsabilidades en el cuidado de familiares entre hombres y mujeres y la eliminación de las desigualdades de género en materia de ingresos y salarios».

${ }^{4}$ Otros Convenios de la OIT que también recogen medidas en materia de conciliación y jornada, aunque estos no fueron ratificados por España, serían, el Convenio 175, de 24 de junio de 1994, sobre el trabajo a tiempo parcial, y el Convenio 183, de 15 de junio de 2000, sobre la protección de la maternidad.

5 Otros instrumentos europeos que regulan la conciliación familiar y la jornada laboral serían las ya mencionadas Carta de Derechos Fundamentales y la Carta Social Europea, el Pacto Europeo por la Igualdad de Género 2011-2020, y la Directivas 2006/54/CE. Sin embargo, a pesar de la evidente relación, no hay referencias a la conciliación en la Directiva 98/23/CEE, sobre tiempo parcial, ni en la Directiva 2003/88/CEE, sobre la ordenación del tiempo de trabajo. 
En cuanto al derecho estatal español, la LOIEMH establece en su artículo 48, apartados 1 y 3 , que, «los derechos de conciliación de la vida personal, familiar y laboral se reconocerán a los trabajadores y las trabajadoras en forma que fomenten la asunción equilibrada de las responsabilidades familiares, evitando toda discriminación basada en su ejercicio", reconociéndose "a los padres el derecho a un permiso y una prestación por paternidad». Esta Ley introdujo varias disposiciones en materia de conciliación y corresponsabilidad en el ET, concretamente introduce un apartado 8 en el artículo 34 - introducido por la Disposición adicional décimo primera de la LOIEMH -. A su vez, el Real Decretoley 6/2019, de 1 de marzo, de medidas urgentes para garantía de la igualdad de trato y de oportunidades entre mujeres y hombres en el empleo y la ocupación, modifica el apartado 4 del artículo 37, lo que supuso que los derechos aquí recogidos fueran individuales e intransferibles al otro progenitor, introduciendo la corresponsabilidad familiar entre mujeres y hombres.

Por otro lado, la redacción del artículo 34.8 ET, «impide superar la percepción demasiado generalizada de que el cuidado familiar no es responsabilidad empresarial, sino que pertenece a la esfera individual y familiar", y olvida que el derecho a la conciliación familiar es un derecho fundamental, como indica el Tribunal Constitucional ${ }^{6}$. De esta forma, en el art. 34.8 ET, deberían estar al mismo nivel el derecho a la ordenación temporal por conciliación familiar y el derecho a que dicho ejercicio no altere esencialmente la organización empresarial, pero dicho artículo «disminuye la eficacia del derecho a la conciliación familiar situándolo en un nivel inferior al derecho a la organización empresarial, condicionando en todo caso su ejercicio a lo establecido en el convenio colectivo». Tanto la LOIEMH como los planes de igualdad podrían haber reajustado este derecho subjetivo a la adaptación de jornada, en vez de seguir centrándose en los permisos y derechos de ausencia (Ballester Pastor, 2012, 66-67). Indica la autora que:

una mayor implicación de la norma estatal podría haber establecido un punto de referencia más susceptible de ser ocupado por los planes de igualdad y/o por los convenios colectivos a efectos de configurar mecanismos de ordenación temporal consecuentes con los objetivos de la corresponsabilidad.

Sin que aquí se pretenda hace un análisis en profundidad cabe matizar que el Plan MECUIDA, que se enmarca dentro de las medidas excepcionales contra el COVID-19 aprobadas por el Real Decreto - Ley 8/2020, de 19 de marzo, a

${ }^{6}$ En la STC 26/2011, de 4 de marzo, se reprocha «el hecho de que los órganos judiciales no se hayan planteado la cuestión de si denegar al trabajador demandante la pretendida asignación del horario nocturno constituía o no un obstáculo para la compatibilidad de su vida familiar y laboral, en atención a las circunstancias concurrentes, supone no valorar adecuadamente la dimensión constitucional ex art. $14 \mathrm{CE}$, en relación con el art. 39.3 CE» (FJ. 6). 
diferencia de lo previsto en materia de adaptación de la jornada de trabajo por motivos de conciliación en el artículo 34.8 del ET, contempla un nuevo derecho a la adaptación horaria y reducción de jornada a efectos de facilitar el cuidado sin que su ausencia pueda implicar ninguna sanción. De esta forma, con esta medida parece configurarse un "derecho subjetivo perfecto" «en favor de las personas trabajadoras interesadas al que no podría negarse (aunque sí a los términos de su ejercicio) la empresa afectada ni por el que se les podría sancionar y/o despedir» (Barrios Baudor, 2020, 5-11).

Respecto a la suspensión del contrato con reserva del puesto de trabajo, se incluyen en el artículo 48 del ET —apartados 4, 5, 6, 7, 8 y 9 modificados por RDL 6/2019-, los supuestos de parto, riesgo durante el embarazo o riesgo durante la lactancia natural, y además se incluye un nuevo artículo 48 bis, en el que se recoge también la suspensión de contrato por paternidad (Disposición décimoprimera de la LOIEMH), considerándose nula la extinción en estos supuestos (art.53.4 ET).

\subsection{Prevención del acoso contra las mujeres en la empresa}

A nivel nacional, podríamos encontrar el fundamento de la protección que protege de las personas trabajadoras frente al acoso sexual y del acoso por razón de sexo en los artículos 10 (derecho a la dignidad), 14 (derecho a la igualdad y no discriminación), 18.1 (derecho al honor y a la intimidad) y en el art. 35.1 (derecho al trabajo) de la Constitución Española. Respecto a estos derechos constitucionales, indica Vallejo Dacosta $(2006,66)$ que:

en todos los supuestos de acoso laboral, es la dignidad de la persona y todos los demás derechos fundamentales — personales e individuales - referenciados en el texto constitucional los que se ven violentados por una actitud de hostigamiento o violencia en el trabajo. Todos los supuestos de acoso laboral sean por los motivos que sean, constituyen, ante todo, vulneración de los derechos de los trabajadores a su dignidad e integridad moral y todos los demás derechos lesionados quedarán absorbidos por éste o bien, simplemente concurrieran unos con otros. Al fin y al cabo, en ambos casos nos encontramos en el plano de los Derechos Fundamentales por lo que las medidas de tutela jurídica serán sustancialmente coincidentes.

Estos derechos fundamentales aparecen recogidos en la definición de acoso sexual y acoso por razón de sexo que contiene la LOIEMH en su artículo 7. En esta definición la LOIEMH elimina la referencia a que el acoso deba ser indeseado, ya que el propio concepto de acoso implica que sea indeseado por su víctima y que esta así lo sienta y denuncie, de tal forma que, si fuera deseado, no sería acoso. Por tanto, establece como elemento definitorio la ofensividad lo que resulta más problemático debido a su interpretación y subjetividad, ya que el sujeto activo puede negar la ofensividad de su acto (Pérez del Río, 2007, 127-190). Según esta autora, el desarrollo normativo de estos derechos consti- 
tucionales se realiza mediante el art. 4.2.d) del ET que reconoce el derecho de toda trabajadora a su integridad física y a una adecuada política de prevención de riesgos laborales, el art. 19 ET según el cual, las personas trabajadoras, en la prestación de sus servicios, tendrán derecho a una protección eficaz en materia de seguridad y salud en el trabajo, y por el texto refundido de la Ley 31/1995, de Prevención de Riesgos Laborales, que, aunque no contiene normas específicas relativas al acoso, «según reitera la doctrina laboralista resulta incontestable que la prevención del acoso entra de lleno en la obligación de protección del empresario como riesgo susceptible de provocar daño en la salud de los trabajadores». De forma más específica, habría que incluir también el artículo 4.2.e ET que, desde las modificaciones introducidas por la LOIEMH, recoge el derecho de las personas trabajadoras «al respeto de su intimidad y a la consideración debida a su dignidad, comprendida la protección frente (...) al acoso sexual y al acoso por razón de sexo».

En la Exposición de Motivos de la LOIEMH se recoge el refuerzo de la protección del derecho de igualdad de oportunidades laborales incluyéndose la protección frente al acoso sexual y al acoso por razón de sexo entre los derechos laborales, así como las consecuencias jurídicas de estas conductas discriminatorias, que, hasta el momento, eran regulados por la LPRL, bajo el carácter extensivo del concepto de normativa de prevención de riesgos laborales que se menciona en el artículo primero de la LPRL, aunque de una forma inadecuada e insuficiente, sumado a una falta de sensibilidad y formación para garantizar una correcta aplicación de la norma (Pérez del Río, 2007, 196).

De manera específica, el artículo 48.1 de la LOIEMH establece como medidas para prevenir el acoso sexual y el acoso por razón de sexo en el trabajo, que «las empresas deberán promover condiciones de trabajo que eviten el acoso sexual y el acoso por razón de sexo y arbitrar procedimientos específicos para su prevención y para dar cauce a las denuncias o reclamaciones que puedan formular quienes hayan sido objeto del mismo. Con esta finalidad se podrán establecer medidas que deberán negociarse con los representantes de los trabajadores, tales como la elaboración y difusión de códigos de buenas prácticas, la realización de campañas informativas o acciones de formación». El segundo apartado de dicho artículo recoge que «los representantes de los trabajadores deberán contribuir a prevenir el acoso sexual y el acoso por razón de sexo en el trabajo mediante la sensibilización de los trabajadores y trabajadoras frente al mismo y la información a la dirección de la empresa de las conductas o comportamientos de que tuvieran conocimiento y que pudieran propiciarlo». Al recogerse literalmente que «las empresas deberán promover (...)», esto supuso la obligación de la empresa de desarrollar medidas preventivas ante el acoso sexual y por razón de sexo en el ámbito laboral, lo que provocó un cambio jurídico trascendental en el ámbito laboral y en materia de prevención del acoso sexual y por razón de sexo y de sanción en caso de su incumplimiento (Kahale Carrillo, 2017, 402). 
Se ha dicho que la LOIEMH no supone un gran avance en materia de prevención de riesgos laborales, por varios motivos, tal y como indica Igartua Miró (2009, 1330), el primero, porque se limita la protección al ámbito de las políticas públicas y las actuaciones van dirigidas a las Administraciones, en segundo lugar, porque, aunque recoge la prevención del acoso, su materialización queda en manos de terceros, en concreto a la negociación colectiva. Y, por último, no existe una coordinación clara entre las obligaciones al empresario en relación a evitar el acoso sexual y por razón de sexo con la política de prevención de riesgos laborales. Sin embargo, consideramos que esta norma da un amplio margen a las empresas y a la negociación colectiva para regular y concretar las distintas medidas específicas de prevención frente al acoso sexual y por razón de sexo. Además, la redacción del art. 48.1. LOIEMH sí establece algunas medidas genéricas de carácter obligatorio para las empresas (Lousada Arochena, 2008, 365-366), como sería la promoción por parte de las empresas de "condiciones de trabajo que eviten el acoso sexual y el acoso por razón de sexo»; el "arbitrar procedimientos específicos para su prevención y para dar cauce a las denuncias o reclamaciones»; "la elaboración y difusión de códigos de buenas prácticas, y la realización de campañas informativas o acciones de formación» mediante la negociación colectiva, lo que obliga a una colaboración con la representación de los trabajadores y trabajadoras. Por otro lado, este artículo también recoge la obligación de la representación del personal a prevenir el acoso sexual y el acoso por razón de sexo.

\section{Conclusiones}

Primera. La situación laboral de las mujeres en España refleja las desigualdades con los hombres en el ámbito laboral que, a pesar del camino ya recorrido y de los avances conseguidos, siguen predominando en la relación con el mercado de trabajo. Resulta relevante cómo la distribución desigual de las tareas domésticas y los cuidados familiares, la falta de corresponsabilidad familiar, junto con la segregación del empleo por sexos suponen factores determinantes en las condiciones de trabajo de las mujeres, que tienen como consecuencias más llamativas la brecha salarial de género y la precariedad del empleo femenino. Siendo la corresponsabilidad y el reparto equitativo de las tareas domésticas y de cuidados tan decisivos en la situación laboral de las mujeres, las políticas deben ir dirigidas fundamentalmente a conseguir una mayor sensibilización desde edades muy tempranas, en la que se eliminen los roles y estereotipos de género que asocian las actividades domésticas y de cuidados a las mujeres. Además de este replanteamiento, es necesario ampliar la oferta pública de los servicios profesionales que cubran estas tareas con el fin de eliminar la doble presencia. Así mismo, la LOIEMH debería recoger que en los planes de igualdad y convenios colectivos se reajuste el derecho a la or- 
denación temporal por conciliación familiar en vistas a mejorar la adaptación de jornada, en vez de seguir manteniendo que las medidas sean principalmente los permisos y derechos de ausencia, aspectos que generan una menor participación y promoción de las mujeres en el ámbito laboral.

Las principales características del empleo femenino, como son la inestabilidad e inseguridad laboral, la doble presencia y la mayor ocupación femenina en el sector servicios, lo que quiere una mayor exigencia emocional y de control de emociones, son factores de riesgo psicosociales que no aparecen únicamente ligados a cuestiones organizacionales o de gestión del trabajo, sino que forman parte de la condición de las mujeres en el trabajo. Es decir, no son factores que exclusivamente formen parte de la cultura organizacional propia de la empresa y se circunscriban a aspectos internos de la entidad empleadora de que se trate, sino que también se deben a cuestiones culturales y sociales, visibles en cualquier ámbito y que, por tanto, también se proyectan en el ámbito laboral. Por ello, las políticas interventivas y preventivas deben, de forma muy ambiciosa, ir más allá de las cuestiones puramente empresariales, que, por supuesto deben regularse de forma explícita en toda la normativa relativa a esta materia, alcanzando las diferentes actuaciones a todos los ámbitos sociales. Esta será la forma de producir cambios estructurales que se acaben traduciendo en una mejora de las condiciones laborales y sociales de las mujeres.

Resulta muy relevante que, en relación con los derechos, en principio temporales, creados para atender a las necesidades derivadas de la COVID-19 con el llamado Plan MECUIDA, el legislativo, por fin, parece haber creado un auténtico derecho subjetivo a la adaptación de la jornada laboral por esas necesidades de conciliación que supera la configuración más tradicional del derecho, más supeditado a lo establecido por el acuerdo individual o el Convenio Colectivo. Cabría plantear qué sería más oportuno, una vez superada la situación de la COVID-19, retornar a lo establecido en el art. 34.8, o, por el contrario, mantener esta medida más favorable para la atención de los intereses conciliatorios de las personas trabajadoras.

Segunda. Respecto al tratamiento jurídico de los riesgos psicosociales en la normativa internacional, comunitaria y estatal, este resulta muy escaso, a pesar de que, sobre todo a nivel internacional y comunitario, se consideren como unos riesgos laborales emergentes y de especial importancia debido a su alta prevalencia y que, como indica la OIT, estos riesgos suponen un reto en materia de seguridad y salud en el trabajo, contempla especialmente el estrés. En el caso nacional, la LPRL no menciona los riesgos psicosociales laborales, aunque se entienden al recogerse en el concepto genérico de riesgos laborales todas aquellas otras características del trabajo, incluidas las relativas a su organización y ordenación, pero sin hacer ni siquiera mención expresa al término «riesgos psicosociales». Sería pues, un gran avance a nivel preventivo que la LPRL dedicase un capítulo al tratamiento, 
definición y tipo de riesgos que se incluirían en la misma, y por supuesto, adoptando de forma más explícita medidas combatirlos. Se debería añadir también a la LPRL un procedimiento de evaluación de riesgos psicosociales laborales específico, en el que también se tenga en cuenta la perspectiva de género y no se limite a la protección de la salud de las mujeres trabajadoras a lo relativo a la maternidad y lactancia natural. La evaluación de los riesgos psicosociales laborales debe comprender la identificación del riesgo, el análisis de su probabilidad y gravedad con el fin de establecer la magnitud de las medidas preventivas e interventivas, y, por último, una evaluación de seguimiento

Si además tenemos en cuenta la perspectiva de género, la normativa no facilita su prevención, y únicamente se centra en riesgos físicos y relacionados con la maternidad y la lactancia natural, aunque sí existen documentos y publicaciones, sobre todo de la OIT, que recogen la importancia de incluir la perspectiva de género en la prevención de riesgos psicosociales laborales. Sí que se podría decir que se tiene en cuenta la perspectiva de género, como es lógico, en el tratamiento de los riesgos psicosociales cuando se alude al acoso sexual y al acoso por razón de sexo, ambos más reconocidos junto con el estrés, tanto a nivel internacional y comunitario, y principalmente en la LOIEMH a nivel estatal. Ciertamente, la LPRL no menciona el acoso sexual y por razón de sexo; sin embargo se entiende que la normativa de prevención de riesgos laborales también la componen las disposiciones recogidas en la LOIEMH sobre esta materia, ya que el primer artículo de la LPRL hace referencia a que la normativa sobre prevención de riesgos laborales está constituida por dicha Ley, otras normas, legales o convencionales, que contengan prescripciones relativas a la adopción de medidas preventivas en el ámbito laboral o susceptibles de producirlas en dicho ámbito. Por ello, la LOIEMH podría introducir modificaciones en la LPRL con el objetivo de incluir la perspectiva de género en el tratamiento, prevención e intervención de los riesgos psicosociales laborales.

Tercera. Por último, en materia de acoso sexual y por razón de sexo, fenómenos que progresivamente se han considerado un problema social y laboral emergente, su normativización tanto por parte de la OIT, de la ONU, del Derecho comunitario y del Derecho español, ha generado distintas definiciones y tratamientos del acoso en el ámbito laboral sobre las que aún no hay mucho consenso, lo que limita su intervención y prevención.

A nivel estatal, la LOIEMH supuso un gran avance al reconocer, aunque sin calificarla así, la violencia de género en el trabajo mediante las distintas referencias que se hacen en ella al acoso, mejorándose tanto su tratamiento normativo en el ámbito laboral como su prevención y tutela. Fue enorme el progreso al recogerse la obligatoriedad de incluir un plan de igualdad en la empresa, aunque haciéndola depender de su tamaño, donde se recogerán, entre otras materias, la prevención del acoso sexual y por razón de sexo. 


\section{Bibliografía}

\section{Doctrina}

Ballester Pastor, M. Amparo (2012). La era de la corresponsabilidad: los nuevos retos de la política antidiscriminatoria. Lan harremanak: Revista de relaciones laborales, (25), 53-77.

Ballester Pastor, M. Amparo (2013). La política de la OIT y de la Unión Europea sobre salud y riesgos psicosociales. Revista Internacional y Comparada de Relaciones Laborales y Derecho del Empleo, 1(4).

Barrios Baudor, Guillermo L. (2020). Adaptaciones y/o reducciones especiales de jornada con ocasión de la crisis sanitaria COVID-19: Plan MECUIDA Adaptations and/or special reductions in working hours due to the health crisis COVID-19: Plan MECUIDA. Revista Aranzadi Doctrinal, (6).

Brunel, Susana, López, Montse y Moreno, Neus (2012). Guía sindical. Mujeres, trabajos y salud. Instituto Sindical de Trabajo, Ambiente y Salud (Istas). Disponible en: https://www.ccoo.es/34711b36c79dab3ef68ba88c2187d63e000001.pdf (Accedido en: 26-06-2020)

Cabeza Pereiro, Jaime y Lousada Arochena, J. Fernando (2000). El acoso sexual como riesgo laboral. Revista Doctrinal Aranzadi Social, (1).

Castaño Ana M., Rueda Ruiz, Begoña, Alcedo Rodríguez, Ángeles y García-IzQUIERDO, Antonio L. (2017). «La evaluación de los riesgos psicosociales en las organizaciones», en García-IzQuierdo, Antonio L. (coord.) Ergonomía y Psicosociología Aplicada a la Prevención de Riesgos Laborales. Servicio de Publicaciones. Universidad de Oviedo.

Carrasquer Oto, Pilar (2009). La doble presencia. El trabajo y el empleo femenino en las sociedades contemporáneas. Tesis doctoral, Universitat Autònoma de Barcelona. Departament de Sociologia.

Cox, Tom, y Griffiths, Amanda J. (1996). «The assessment of psychosocial hazards at work» en Schabrace, Marc J., Winnubst, Jacques. A. M. y Cooper Cary. L. (Eds.), Handbook of Work and Health Psychology. Chichester: Wiley and Sons.

García Jiménez, Manuel y Olarte Encabo, Sofía (2010). La regulación de los riesgos psicosociales en España: experiencia y prospectiva. Revista de Prevención de Riesgos Psicosociales y bienestar en el trabajo, 1, 13-47. Disponible en: https://www.juntadeandalucia.es/empleo/webiaprl/larpsico/sites/es.empleo.webiaprl.larpsico/files/recursos/revista_cientifica/RevistaLarpsico01.pdf (Accedido: 23-03-2020).

García Viña, Jordi (2013). La incidencia del Acuerdo Marco Europeo sobre Acoso y Violencia en el Trabajo. Boletín de la Sociedad Internacional de Derecho del Trabajo y de la Seguridad Social (23), 1-16. Disponible en: https://islssl.org/wp-content/ uploads/2013/03/Spain-Laincidencia-Vina.pdf (Accedido: 18-06-2020)

Gollac, Michel y Bodier, Marceline (2011). Mesurer les facteurs psychosociaux de risque au travail pour les maîtriser Rapport du Collège d'expertise sur le suivi des risques psychosociaux au travail, faisant suite à la demande du Ministre du travail, de l'emploi et de la santé. Disponible en: https://travail-emploi.gouv.fr/IMG/pdf/rapport_SRPST_ definitif_rectifie_11_05_10.pdf Accedido: 18-06-20)

Grau Pineda, Carmen (2017). Sobre la imperiosa necesidad de incorporar el sesgo de género en la gestión de los riesgos psicosociales. Estudios financieros. Revista de trabajo y seguridad social, 408, 23-58.

Greenhalgh, Leonard y Rosenblatt, Zehava (1984). Job insecurity: Toward conceptual clarity. Academy of Management review, 9(3), 438-448. 
Greenhaus, Jeffrey H. y Beutell, Nicholas J. (1985). Sources of conflict between work and family roles. Academy of management review, 10(1), 76-88

Igartua Miró, Teresa M. (2008). Prevención de Riesgos Laborales en clave de género en Andalucía. Temas laborales: Revista andaluza de trabajo y bienestar social, 3(100), 1313-1352.

Kahale Carrillo, Djamil T. (2017). «El acoso (laboral, sexual y por razón de sexo)» en Sánchez Trigueros, Carmen (dir.) El principio de igualdad en la negociación colectiva. Ministerio de Trabajo e Inmigración, Subdirección General de Informacion Administrativa y Publicaciones.

López Cumbre, Lourdes (2020). Planes de igualdad: una realidad jurídica con más desarrollo. Revista CESCO De Derecho De Consumo, (36), 36-46. Disponible en: https:// revista.uclm.es/index.php/cesco/article/view/2574 (Accedido: 12-12-2020).

López Nuñez, M. Inmaculada (2020). «Riesgos psicosociales emergentes: el conflicto trabajo-familia» en Correa Carrasco, Manuel y Quintero Lima, M. Gema (coords.) Los nuevos retos del trabajo decente: la salud mental y los riesgos psicosociales (ODS 3,5,8,10). Madrid: Universidad Carlos III. Disponible en: http://hdl.handle.net/10016/29725 (Accedido: 12-12-2020).

Lousada Arochena, Fernando J. (2008). "Acoso sexual y acoso sexista» en Lousada Arochena, Fernando J. (coord.) El principio de igualdad en la negociación colectiva. Ministerio de Trabajo e Inmigración, Subdirección General de Informacion Administrativa y Publicaciones.

Luque Parra, Manuel y Sánchez Torres, Esther (2008). Comentario práctico a la Ley de Prevención de Riesgos Laborales. Cataluña: UGT. Disponible en: http://portal.ugt.org/ saludlaboral/publicaciones_new/files_librocat_comentariopractico/publication.pdf (Accedido: 12-12-2020).

Martínez IÑigo, David (2001). Evolución del concepto de trabajo emocional: dimensiones, antecedentes y consecuentes. Una revisión teórica. Revista de Psicología del Trabajo y de las Organizaciones, 17(2), 131-153.

Martínez Moreno, Carolina (2019). Brecha salarial de género y discriminación retributiva: causas y vias para combatirlas. Albacete: Editorial Bomarzo

Molina Navarrete, Cristobal (2011). El recargo de prestaciones por infracción del deber de evaluar los riesgos psicosociales: la doctrina judicial hace «justicia disuasoria. Aranzadi Social, 83, 1-9.

Moreno JimÉnEZ, Bernardo (2011). Factores y riesgos laborales psicosociales: conceptualización, historia y cambios actuales. Medicina y Seguridad del Trabajo, 57(Supl. 1), 4-19.

Moreno Jiménez, Bernardo y Báez León, Carmen (2010). Factores y riesgos psicosociales, formas, consecuencias, medidas y buenas prácticas. Universidad Autónoma de Madrid, 19. Publicado por el Instituto Nacional de Seguridad e Higiene en el Trabajo. Disponible en: https://www.insst.es/documents/94886/96076/Factores+y+riesgos+psi cosociales $\% 2 \mathrm{C}+$ formas $\% 2 \mathrm{C}+$ consecuencias $\% 2 \mathrm{C}+$ medidas $+\mathrm{y}+$ buenas+pr $\% \mathrm{C} 3 \% \mathrm{~A} 1 \mathrm{cti}$ cas/c4cde3ce-a4b6-45e9-9907-cb4d693c19cf (Accedido: 25-03-2020)

Peiró, José M. y Soler, Ángel (2020). El impulso al teletrabajo durante el COVID-19 y los retos que plantea. Laboratorio de Análisis y Evaluación de Politicas Públicas. Instituto Valenciano de Investigaciones Económicas. Disponible en: https://www.ivie.es/ wp-content/uploads/2020/05/11.Covid19IvieExpress.El-impulso-al-teletrabajo-durante-el-COVID-19-y-los-retos-que-plantea.pdf (Accedido: 10-07-2020) 
Pérez del Rio, Teresa M. (2007). La violencia de género en el trabajo: el acoso sexual y el acoso moral por razón de género. Temas laborales: revista andaluza de trabajo y bienestar social, (91), 175-204.

Pons Carmena, María (2020). Aproximación a los nuevos conceptos sobre violencia y acoso en el trabajo a partir de la aprobación del Convenio OIT 190. LABOS Revista de Derecho del Trabajo y Protección Social, 1(2), 30-60.

Ramos, José y Gómez, Alicia (2020). ¿Por qué los retos de la conciliación en tiempos de COVID-19 son todavía mayores para las mujeres? Laboratorio de Análisis y Evaluación de Politicas Públicas. Instituto Valenciano de Investigaciones Económicas. Disponible en: https://www.ivie.es/wp-content/uploads/2020/06/16.Covid19_IvieExpress_Porqu\%C3\%A9-los-retos-de-la-concilacion-en-tiempos.pdf (Accedido: 10-07-2020)

Rebollo Quintela, Nuria y Muñoz Cantero, Jesús M. (2017). Inseguridad, precariedad e inestabilidad: retrato de la inserción laboral femenina. Insecurity, precariousness and instability: portrait of female employment. Revista de Estudios e Investigación en Psicología y Educación, 4(2), 122-131.

RodríGuez-MuÑoz, Alfredo (2017). Riesgos psicosociales en el entorno laboral: una perspectiva de género. Informe sobre salud laboral desde la perspectiva de género. Getafe: Universidad Carlos III de Madrid, pp. 16-25.

Russell Hochschild, Arlie (1983). The managed heart: commercialization of human feeling. California: University of California Press.

SAlas Nicás, Sergio (2018). Inseguridad laboral en España: caracterización, distribución y asociación con salud. Tesis doctoral, Universitat Autònoma de Barcelona.

SAnZ Vergel, Ana Isabel (2011). Conciliación y salud laboral: ¿una relación posible?: Actualidad en el estudio del conflicto trabajo-familia y la recuperación del estrés. Medicina y Seguridad del Trabajo, 57(Supl. 1), 115-126.

Sierra Benítez, Esperanza. M. (2020). Breve referencia a la negociación colectiva en la regulación del trabajo a distancia en el RD-ley 28/2020. Noticias CIELO, (8), 8. Disponible en: : http://www.cielolaboral.com/wp-content/uploads/2020/10/sierra_noticias_cielo_n8_2020.pdf (Accedido: 12-12-2020)

Sora Miana, Beatriz, Caballer Hernández, Amparo y Peiró Silla, José M. (2014). La inseguridad laboral y sus consecuencias en un contexto de crisis económica. Papeles del Psicólogo, 35(1), 15-21.

Tereso Ramírez, Leonor y Cota Elizalde, Beatriz D. (2017) La doble presencia de las mujeres: conexiones entre trabajo no remunerado, construcción de afectos-cuidados y trabajo remunerado. Margen: Revista de Trabajo Social y Ciencias Sociales (85), 1-12.

Vallejo Dacosta, Ruth (2006). Acoso sexual y acoso por razón de sexo. Riesgos de especial incidencia en la mujer trabajadora. Trabajo: Revista iberoamericana de relaciones laborales, (17), 55-84.

Velázquez Fernández, Manuel (2020). "Cómo se está legislando sobre los riesgos psicosociales en el trabajo en La UE» en Correa Carrasco, Manuel y Quintero Lima, M. Gema (coords.) Los nuevos retos del trabajo decente: la salud mental y los riesgos psicosociales (ODS 3,5,8,10). Madrid: Universidad Carlos III. Disponible en: http:// hdl.handle.net/10016/29725 (Accedido: 12-12-2020).

\section{Documentación}

Agencia Europea de Seguridad y Salud en el Trabajo (2007). Expert forecast on emerging psychosocial risks related to occupational safety and health. Disponible en: https:// osha.europa.eu/en/publications/reports/7807118 (Accedido: 23/03/2020)

Comisión de las Comunidades Europeas (2002). ComunicaCión de la Comisión, de 11 de marzo de 2002, relativa a la estrategia comunitaria de salud y seguridad en el 
trabajo (2002-2006). COM (2002) 118 - no publicada en el Diario Oficial. Disponible en: https://eurlex.europa.eu/legal-content/ES/TXT/?uri=LEGISSUM\%3Ac11147 (Accedido: 17-04-2020).

Comisión de las Comunidades Europeas (2007). Comunicación de la Comisión al Parlamento Europeo, al Consejo, al Comité Económico y Social y al Comité de las Regiones (COM (2007) 62 - final). Mejorar la calidad y la productividad en el trabajo: estrategia comunitaria de salud y seguridad en el trabajo, 2007-2012. Disponible en: https:// eurlex.europa.eu/LexUriServ/LexUriServ.do?uri=COM:2007:0062:FIN:ES:PDF (Accedido: 17-04-2020).

INE (2016). Horas semanales dedicadas a actividades de cuidados y tareas del hogar. Espańa y UE-28. 2016. Madrid: Instituto Nacional de Estadística. Disponible en: https://www.ine.es/jaxi/Datos.htm?path=/t00/mujeres_hombres/tablas_1/ 10/\&file=ctf03002.px (Accedido: 26-03-2020)

Instituto De la Mujer (2006). El acoso sexual a las mujeres en el ámbito laboral: resumen de resultados. Madrid: Ministerio de Trabajo y Asuntos Sociales. Disponible en: https://www.navarra.es/NR/rdonlyres/D91FE499-4898-4EDD-AA09-213A8AF I $22 E A /$ I $53594 /$ MTASEsTUdioAcosoSEXUAL.pDF (ACCEDIDO: 20/03/2020)

Instituto Sindical de Trabajo, Ambiente y Salud (2019). Exposiciones psicosociales laborales en España: una mirada de clase y de género. Madrid: Ministerio de Trabajo, Migraciones y Seguridad Social. Disponible en: https://istas.net/sites/default/ files/201904/INFORMEGE\%CC\%81NEROYCLASE.pdf (Accedido: 03/04/2020)

Instituto Nacional de Seguridad e Higiene en el Trabajo (i999). Nota técnica de prevención 507: Acoso sexual en el trabajo. Madrid: Ministerio de Trabajo y Asuntos Sociales. Disponible en: https://www.insst.es/documents/94886/327064/ntp_507. pdf/ea11e310-ef40-4572-bf27-fd4fa908523b (Accedido: 30-03-2020)

Moncada, S., Llorens, C., Andrés, R. (Centro de Referencia en Organización del Trabajo y Salud-ISTAS), Moreno, N. (CCOO de Catalunya) y Molinero, E. (Departament d'Empresa i Ocupació, Generalitat de Catalunya) (2014). Manual del método CoPsoQistas21 (versión 2) para la evaluación y la prevención de los riesgos psicosociales en empresas con 25 o más trabajadores y trabajadoras VERSIÓN MEDIA. Barcelona: Instituto Sindical de Trabajo, Ambiente y Salud. Disponible en:https://copsoq.istas21.net/ficheros/documentos/v2/manual\%20Copsoq\%202(24-07-2014).pdf (Accedido 25-03-2020)

OIT (1998). Enciclopedia de la Seguridad y la salud en el Trabajo. Tomo II, parte V. Madrid: Ministerio del Trabajo y Asuntos Sociales. Disponible en: https://www.insst.es/ documents/94886/162520/Cap\%C3\%ADtulo+34.+Factores+psicosociales+y+de+org anizaci\%C3\%B3n (Accedido: 23-03-2020)

Organización Internacional del Trabajo (OIT), (1999). Conferencia Internacional del Trabajo (N. 87). Memoria del Director General: Trabajo decente. Ginebra: Oficina Internacional del Trabajo. Disponible en: https:/www.ilo.org/public/spanish/standards/relm/ilc/ilc87/rep-i.htm (Accedido: 18-04-2020)

Organización Mundial de la Salud (2006). Constitución de la Organización Mundial de la Salud adoptada por la Conferencia Sanitaria Internacional, celebrada en Nueva York del 19 de junio al 22 de julio de 1946. 45. a edición, octubre de 2006. Disponible en: https:// www.who.int/governance/eb/who_constitution_sp.pdf (Accedido: 23-03-2020) 